\title{
Modest Neuropsychological Deficits Caused by Reduced Noradrenaline Metabolism in Mice Heterozygous for a Mutated Tyrosine Hydroxylase Gene
}

\author{
Kazuto Kobayashi, ${ }^{1}$ Yukihiro Noda, ${ }^{2}$ Natsuki Matsushita, ${ }^{1}$ Kazuhiro Nishii, ${ }^{3}$ Hirohide Sawada, ${ }^{3}$ \\ Toshiharu Nagatsu, ${ }^{3}$ Daiichiro Nakahara, ${ }^{4}$ Ryoji Fukabori, ${ }^{5}$ Yasunobu Yasoshima, ${ }^{5}$ Takashi Yamamoto, ${ }^{5}$ \\ Masami Miura,, ${ }^{6}$ Masanobu Kano,, ${ }^{6}$ Takayoshi Mamiya, ${ }^{2}$ Yoshiaki Miyamoto, ${ }^{2}$ and Toshitaka Nabeshima$^{2}$ \\ ${ }^{1}$ Department of Molecular Genetics, Institute of Biomedical Sciences, Fukushima Medical University School of Medicine, \\ Fukushima 960-1295, Japan, 2Department of Neuropsychopharmacology and Hospital Pharmacy, Nagoya University \\ School of Medicine, Nagoya 466-8560, Japan, 3/nstitute for Comprehensive Medical Science, Graduate School of \\ Medicine, Fujita Health University, Toyoake 470-1192, Japan, ${ }^{4}$ Department of Psychology, Hamamatsu University School \\ of Medicine, Hamamatsu 431-3192, Japan, 5 Department of Behavioral Physiology, Faculty of Human Sciences, Osaka \\ University, Suita 565-0871, Japan, and ${ }^{6}$ Department of Physiology, Kanazawa University School of Medicine, Kanazawa \\ 920-8640, Japan
}

Tyrosine hydroxylase $(\mathrm{TH})$ is the initial and rate-limiting enzyme for the biosynthesis of catecholamines that are considered to be involved in a variety of neuropsychiatric functions. Here, we report behavioral and neuropsychological deficits in mice carrying a single mutated allele of the TH gene in which TH activity in tissues is reduced to $\sim 40 \%$ of the wild-type activity. In the mice heterozygous for the TH mutation, noradrenaline accumulation in brain regions was moderately decreased to $73-80 \%$ of the wild-type value. Measurement of extracellular noradrenaline level in the frontal cortex by the microdialysis technique showed a reduction in high $\mathrm{K}^{+}$-evoked noradrenaline release in the mutants. The mutant mice displayed impairment in the water-finding task associated with latent learning performance.
They also exhibited mild impairment in long-term memory formation in three distinct forms of associative learning, including active avoidance, cued fear conditioning, and conditioned taste aversion. These deficits were restored by the drug-induced stimulation of noradrenergic activity. In contrast, the spatial learning and hippocampal long-term potentiation were normal in the mutants. These results provide genetic evidence that the central noradrenaline system plays an important role in memory formation, particularly in the long-term memory of conditioned learning.

Key words: tyrosine hydroxylase; noradrenaline system; latent learning; associative learning; long-term memory; gene targeting
The noradrenaline system in the CNS is known to be involved in a wide variety of neurological and psychological functions, such as cognition, attention, emotion, and memory formation (for review, see Foote et al., 1983; Robbins and Everitt, 1995). The central noradrenaline system originates from certain cell groups in the locus ceruleus and the lateral tegmental area in the brain stem and projects to discrete brain regions, including the cerebral cortex, amygdala, hippocampus, and thalamus through different noradrenergic bundles (Moore and Card, 1984). These cell groups have extensive collaterals and dense terminal arborizations. At the cellular level, noradrenaline modulates neuronal excitability by opening or closing ion channels depending on the receptor subtypes and second messengers involved (for review, see Nicoll et al., 1990; Dohlman et al., 1991). Moreover, many clinical investigations have implicated alterations in the noradren-

\footnotetext{
Received Sept. 27, 1999; revised Dec. 20, 1999; accepted Jan. 5, 2000.

This work was supported by grants-in-aid from the Ministry of Education, Science, Culture, and Sports of Japan (K.K., T.Y., and T.N.), Core Research for Evolutional Science and Technology of Japan Science and Technology Corporation (K.K., M.M., and M.K.), the Mitsubishi Foundation of Japan (K.K.), and the Center of Excellence (T.N.). We thank H. Sano and H. Okada for biochemical analysis of catecholamines.

Drs. Kobayashi and Noda contributed equally to this work.

Correspondence should be addressed to Dr. Kazuto Kobayashi, Department of Molecular Genetics, Institute of Biomedical Sciences, Fukushima Medical University School of Medicine, Fukushima 960-1295, Japan. E-mail: kazuto@cc.fmu.ac.jp Copyright (C) 2000 Society for Neuroscience $0270-6474 / 00 / 202418-09 \$ 15.00 / 0$
}

aline system in the pathological states of neuropsychiatric diseases, such as depression, anxiety disorder, and attention-deficit disorder (Rubin et al., 1985; Charney et al., 1987, 1992; Oades, 1987; Schatzberg et al., 1989). Some of the drugs that alter the central noradrenergic action improve the symptoms of these disorders.

Tyrosine hydroxylase ( $\mathrm{TH})$ catalyzes the conversion of L-tyrosine to L-3,4-dihydroxyphenylalanine, which is the first and rate-limiting step of the biosynthesis of catecholamines (Nagatsu et al., 1964). The expression level and activity of TH are regulated by transcriptional control of gene expression or by posttranslational modification of the protein via phosphorylation (Zigmond et al., 1989). The regulatory mechanism of the $\mathrm{TH}$ reaction is generally considered to play a key role in controlling the catecholaminergic action. A null mutation in the mouse TH gene causes profound depletion of catecholamines and lethality of the homozygous mutants at the perinatal stage because of cardiovascular failure (Kobayashi et al., 1995; Zhou et al., 1995; Rios et al., 1999). On the other hand, mice heterozygous for the TH mutation are apparently normal in their development and gross behavior, but they display a decline in $\mathrm{TH}$ activity in their tissues because of the gene dosage effect (Kobayashi et al., 1995).

In the present study, we examined behavioral and neuropsychological functions involving the noradrenaline system in $\mathrm{TH}^{+/-}$heterozygous mutant mice. We found that the mutant 
mice had a reduction in the biosynthesis and release of noradrenaline in the brain. This decrement resulted in impairments in latent learning and long-term memory in three distinct forms of associative learning (active avoidance, fear conditioning, and conditioned taste aversion). In contrast, the spatial learning and hippocampal long-term potentiation (LTP) were normal in the mutants. These data indicate that the latent learning and longterm memory of conditioned learning are highly susceptible to a reduction in the brain noradrenaline level.

\section{MATERIALS AND METHODS}

Animals. Gene targeting of the mouse TH locus was described in our previous study (Kobayashi et al., 1995). The TH mutation was introduced by homologous recombination with embryonic stem (ES) cells obtained from the $129 / \mathrm{SvJ}$ mouse strain. The ES cells with the mutation were injected into C57BL/6J blastocysts, which were implanted into the uterine horns of ICR pseudopregnant females. Male chimeras were mated with $\mathrm{C} 57 \mathrm{BL} / 6 \mathrm{~J}$ females. Mice heterozygous for the mutation were backcrossed to C57BL/6J mice for more than five generations. All mice used in the present study were littermates of 12-16 weeks of age, and the biochemical, behavioral, and electrophysiological data were compared between the wild-type and $\mathrm{TH}^{+/-}$heterozygous mutant mice. Animal care and handling procedures were in accordance with the guidelines established by the Experimental Animal Center of Fukushima Medical University.

Neurochemical analysis. Noradrenaline accumulation in the brain regions was determined with an automatic HPLC system based on a spectrofluorimetric method (Kobayashi et al., 1994). Noradrenaline release evoked by membrane depolarization was measured by the microdialysis method (Nakahara et al., 1993). Mice were anesthetized with sodium pentobarbital $(50 \mathrm{mg} / \mathrm{kg}$, i.p.) and surgically implanted with a microdialysis probe (membrane length of $3 \mathrm{~mm}, 0.22 \mathrm{~mm}$ in outer diameter, $10 \mu \mathrm{m}$ in wall thickness; Cuprophan; EICOM, Kyoto, Japan) into the frontal cortex using the coordinates anteroposterior +0.7 , lateromedial +0.3 , and dorsoventral -0.5 from bregma and dura, according to the atlas of Franklin and Paxinos (1997). After surgery, animals were allowed to recover for at least $24 \mathrm{hr}$. Artificial CSF (ACSF) was pumped through the probe at $1 \mu \mathrm{l} / \mathrm{min}$ for $2 \mathrm{hr}$, and dialysis samples were collected at $60 \mathrm{~min}$ intervals. For stimulation of noradrenaline release, ACSF containing $100 \mathrm{~mm} \mathrm{~K}^{+}$was perfused for $30 \mathrm{~min}$ at the beginning of the third and sixth fractions (S1 and S2). The amount of noradrenaline in each fraction was determined by the HPLC system equipped with an electrochemical detector. After the microdialysis experiments, mice were deeply anesthetized with sodium pentobarbital. Brains were removed and stored in $10 \%$ formaline for $>1$ week. Frozen brain sections $(30 \mu \mathrm{m}$ thickness) were stained with cresyl violet for the verification of probe placement sites. The histological examination confirmed probe placement within the frontal cortex without apparent tissue damage.

Behavioral analysis. The water-finding test was performed according to the method described by Ichihara et al. (1993). The apparatus consisted of an open field $(30 \times 50 \times 15 \mathrm{~cm})$ equipped with an alcove $(10 \times 10 \times$ $10 \mathrm{~cm}$ ) and a metal drinking tube inserted into the center of the alcove ceiling. Mice were not water deprived before the training trial and were placed individually into the open field to explore the environment freely for $3 \mathrm{~min}$. After the training trial, the mice were returned to their home cages and deprived of water for $24 \mathrm{hr}$ before the test trial. Each mouse was again placed in the same corner of the test apparatus, and the time between onset of exploration and initiation of drinking from the water tube was recorded as drinking latency. In addition, each mouse was scored for the time taken to enter the alcove (entering latency) and for the time between entering the alcove and drinking water (finding latency). Mice that had not been exposed to the training trial were also given the same test trials as the nontrained controls, and their latency data were recorded.

For the active avoidance test (Nishii et al., 1998), the shuttle box apparatus consisted of two compartments with a grid floor, including one light and one dark chamber $(16 \times 11 \times 11 \mathrm{~cm})$, which were separated by a guillotine door. Each trial started by placing an animal in the dark compartment. A tone stimulus $(80 \mathrm{~dB})$ was given for $5 \mathrm{sec}$, and an electric shock $(0.2 \mathrm{~mA})$ for $5 \mathrm{sec}$ was then delivered to the feet with a scrambled shock generator. When the tone stimulus was given, the mouse moved into the light compartment before the onset of the foot shock, and such response was counted as an avoidance. The mouse was manually re- turned to the dark compartment, and the subsequent trials were performed. Each animal was given 10 trials/d for 7 consecutive days.

For the cued fear conditioning test (Oike et al., 1999), mice were placed in a neutral cage $(20 \times 31 \times 11 \mathrm{~cm})$, and the freezing response was measured for $1 \mathrm{~min}$ in the absence of sound (preconditioning phase). In the conditioning phase, mice were placed in the training cage $(25 \times 30 \times$ $11 \mathrm{~cm}$ ) equipped with a metal floor, and the pretrial time of 2 min was followed by a $15 \mathrm{sec}$ tone $(80 \mathrm{~dB})$. During the last $5 \mathrm{sec}$ of the tone stimulus, a foot shock of $0.8 \mathrm{~mA}$ was delivered through a shock generator. This procedure was repeated four times with $15 \mathrm{sec}$ intervals. One and 24 $\mathrm{hr}$ after the conditioning, the freezing response to the tone stimulus was measured for $1 \mathrm{~min}$ in the presence of a continuous sound in the neutral cage. The response was monitored by an animal movement analyzer (Scanet SV-10AQ; Toyo Sangyo, Toyama, Japan) and evaluated as a suppression of locomotor activity by the tone stimulus.

For the conditioned taste aversion test (Yamamoto et al., 1994), mice were shaped for $5 \mathrm{~d}$ before the start of the paradigm. During shaping, the mice were deprived of water for $23 \mathrm{hr}$ and were presented with water from one drinking bottle once a day, during a 10 min session in the test cage $(25 \times 30 \times 11 \mathrm{~cm})$. The mice were allowed to drink water for another $50 \mathrm{~min}$ to avoid dehydration. On the day of conditioning, the animals received $0.5 \mathrm{M}$ sucrose instead of water. Sucrose intake was measured for $10 \mathrm{~min}$ (preconditioning phase), and immediately thereafter they were treated intraperitoneally with $0.15 \mathrm{~m}$ lithium chloride $(2 \%$ of body weight) as the malaise-inducing agent. This conditioning was repeated for 3 consecutive days. Taste aversion was assessed 1 and $2 \mathrm{~d}$ after the conditioning by measuring sucrose intake for $10 \mathrm{~min}$.

The Morris water maze test was conducted in a circular pool of $1.2 \mathrm{~m}$ in diameter and filled with water at a temperature of $18.0 \pm 0.5^{\circ} \mathrm{C}$ as described previously (Manabe et al., 1998). A hidden platform $(7 \mathrm{~cm}$ in diameter) was used. The mice were given three trials (one block) for 7 consecutive days during which the platform was left in the same position. The time taken to locate the escape platform (escape latency) was determined in each trial. Twenty-four hours after the last training trial, the mice were given a probe test during which the platform was removed, and they were allowed $60 \mathrm{sec}$ to search for the pool.

Electrophysiology. Transverse hippocampal slices $(400 \mu \mathrm{m})$ were prepared by standard techniques and media (Grant et al., 1992). They were maintained in a submerged recording chamber that was perfused with ACSF equilibrated with $95 \% \mathrm{O}_{2}-5 \% \mathrm{CO}_{2}$ at $32 \pm 0.5^{\circ} \mathrm{C}$. Field EPSPs were recorded using glass micropipettes filled with $1 \mathrm{M} \mathrm{NaCl}$ in the stratum radiatum of the CA1 region or in the stratum lucidum of the CA3 region. Test stimulus was applied at $0.05 \mathrm{~Hz}$ to the Schaffer collateralcommissural afferents for the CA1 responses and to the mossy fiber pathway for the CA3 responses. The LTP-inducing conditioning stimulus for the CA1 was 10 bursts of tetanus $(100 \mathrm{~Hz}, 5$ pulses) repeated at $5 \mathrm{~Hz}$. That for the CA3 was one train of tetanus at $100 \mathrm{~Hz}$ for $1 \mathrm{sec}$.

\section{RESULTS}

\section{Modified noradrenaline metabolism in the TH mutant mice}

The $\mathrm{TH}$ activity in the tissues of the $\mathrm{TH}^{+/-}$heterozygous mutants was $\sim 40 \%$ of the wild-type activity because of the gene dosage effect, but their catecholamine levels in the whole brain showed nearly normal values (Kobayashi et al., 1995). To further characterize the influences of the reduced $\mathrm{TH}$ activity on noradrenaline metabolism, we measured noradrenaline accumulation in dissected brain tissues (Fig. 1). The noradrenaline levels in various brain regions of the heterozygous mutants were moderately reduced relative to the corresponding wild-type values. In particular, the noradrenaline levels were significantly reduced $(p<0.05$, Student's $t$ test) in the frontal cortex (to 78\%), midbrain (to $80 \%$ ), and hypothalamus (to $73 \%$ ). In the hippocampus and pons medulla, the levels tended to decrease to 79 and $80 \%$ of the controls, respectively. Then, we measured spontaneous and high $\mathrm{K}^{+}$-evoked noradrenaline release in the frontal cortex by the microdialysis technique (Fig. 2). There was no difference in spontaneous release of noradrenaline between the wild-type and heterozygous mutant mice. In response to initial high $\mathrm{K}^{+}$stimulation (S1), the extracellular noradrenaline level 


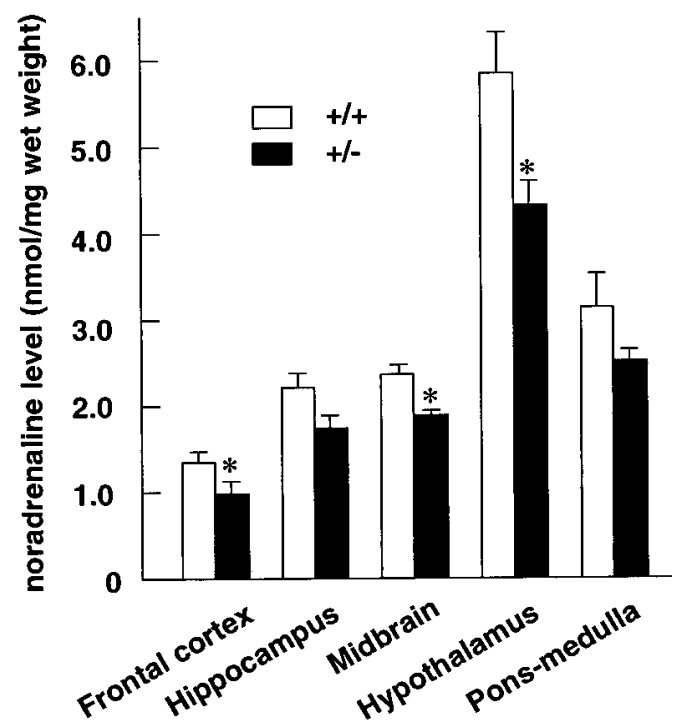

Figure 1. Noradrenaline accumulation in the brain. Various brain regions were dissected from wild-type and heterozygous mutant littermates. They were subjected to catecholamine analysis with an automatic HPLC system. Values represent mean \pm SEM of data from 12 mice. ${ }^{*} p<0.05$, significant difference from the wild-type level according to Student's $t$ test.

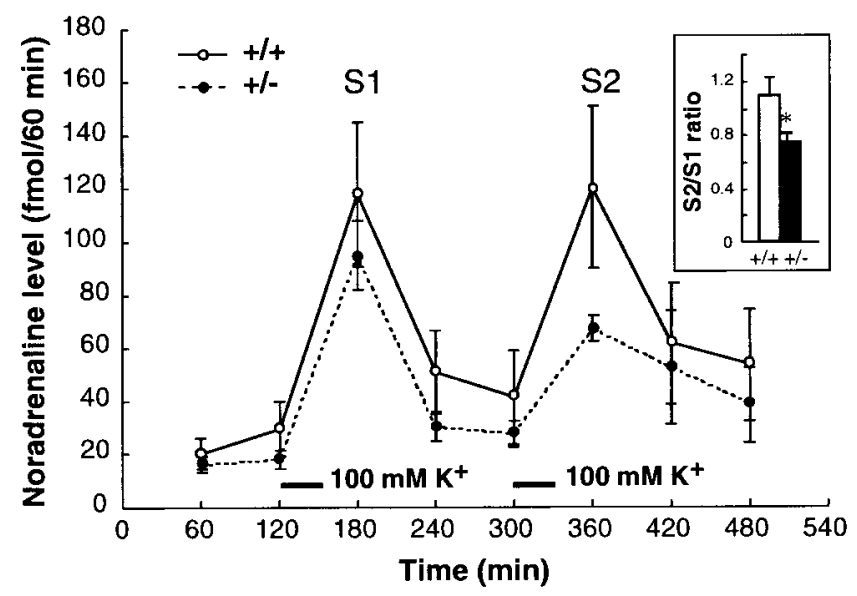

Figure 2. Noradrenaline release in the frontal cortex. Extracellular noradrenaline levels were determined by the microdialysis technique. The high $\mathrm{K}^{+}$solution was perfused for $30 \mathrm{~min}$ as indicated by the horizontal bars. The resulting peak fractions of noradrenaline release (S1 and S2) are indicated. Values are expressed as mean \pm SEM of data from six wildtype and five heterozygous mice. Inset shows the relative ratio S2/S1 based on the microdialysis data. ${ }^{*} p<0.05$, significant difference from the wild-type ratio according to Student's $t$ test.

was increased in both wild-type and heterozygous mutant mice. The value of the S1 fraction of the mutant decreased by only $18 \%$ from the wild-type value. During the second high $\mathrm{K}^{+}$stimulation (S2), the extracellular noradrenaline level was elevated to an extent comparable with that during the initial stimulation in the wild-type, whereas the noradrenaline release was evidently diminished in the heterozygous mutants. The value of the S2 fraction of the mutant was $56 \%$ of the wild-type control. The $\mathrm{S} 2 / \mathrm{S} 1$ ratio, an indicator to evaluate the capacity of noradrenaline stores, was calculated. The ratio of the heterozygote $(0.75 \pm 0.08)$ was significantly smaller than that of the wild-type $(1.09 \pm 0.15)$ $(p<0.05)$. Thus, the noradrenaline stores of the mutant were more liable to be depleted than those of the wild type. These results indicate that the accumulation and release of noradrenaline were reduced in the mutant as a consequence of the decreased $\mathrm{TH}$ activity.

\section{Impaired latent learning in the mutant}

Latent learning is the phenomenon in which animals learn a maze at a faster rate if they have been preexposed to the environment (Mackintosh, 1975; Ettenberg et al., 1983). Chemical lesion of noradrenergic neurons is known to impair the acquisition of latent learning in the water-finding test (Ichihara et al., 1993). In this test, a nonwater-deprived animal is placed in an environment containing a water tube during a training trial. Then the animal is water-deprived for $1 \mathrm{~d}$ and placed back into the same environment for the test of the learning performance. To test whether the modified noradrenaline metabolism would affect the latent learning, we applied the water-finding test to wild-type and $\mathrm{TH}^{+/-}$ heterozygous littermates. The locomotor activity and the exploratory behavior during the training trial, including the time elapsed before starting movement and the frequency of approach to the water tube, were indistinguishable between the two genotypes (data not shown). As shown in Figure $3 A$, the latencies for the finding and drinking performances were not significantly different between the nontrained wild-type and heterozygous mutants. However, when the wild-type mice were preexposed to the test apparatus, the latencies for the finding and drinking performances became significantly shorter than those in the nontrained wild-type (finding latency, $p<0.05$; drinking latency, $p<$ 0.01 ) (Fig. $3 A$ ). In marked contrast, the training did not shorten the latencies in the heterozygous mutant, suggesting the impairment of latent learning.

If the aforementioned learning deficit in the heterozygous mutant would be caused by the reduction in the noradrenaline level in the brain, the performance is expected to be improved by manipulations that activate the noradrenaline system. To test this possibility, we used a noradrenaline reuptake inhibitor, desipramine, to stimulate the noradrenergic activity. The wild-type and heterozygous mutant mice were treated with desipramine (7.5 $\mathrm{mg} / \mathrm{kg}$, i.p.) or saline before exposure to the test apparatus (Fig. $3 B$ ). In the heterozygous mutant, the latencies for both finding and drinking performances after training were significantly shorter in the desipramine treatment group than those in the saline treatment group (finding latency, $p<0.01$; drinking latency, $p<0.01$ ) (Fig. 3B). On the other hand, the desipramine treatment did not affect the latencies in the wild-type mice. The latencies of the desipramine-treated heterozygous mutant were comparable with those of the wild-type mice. These results suggest that the deficit in latent learning in the heterozygous mutant is attributed predominantly to the reduced noradrenaline level in the brain. Also, the failure to improve the learning performance in the wild type by desipramine treatment suggests that the normal level of noradrenaline is sufficient for the latent learning.

\section{Impaired associative learning in the mutant}

Active avoidance is a behavioral paradigm for evaluating associative learning by monitoring the performance of animals to escape an aversive unconditioned stimulus (US) that has been paired with a conditioned stimulus (CS). Noradrenaline depletion by chemical lesion is reported to cause deficits in the acquisition of active avoidance learning (Archer et al., 1982). Thus, we examined whether the altered noradrenaline metabolism in the $\mathrm{TH}^{+/-}$ heterozygous mutant was accompanied by deficits in active avoidance learning. We used a shuttle box paradigm in which a tone 
A

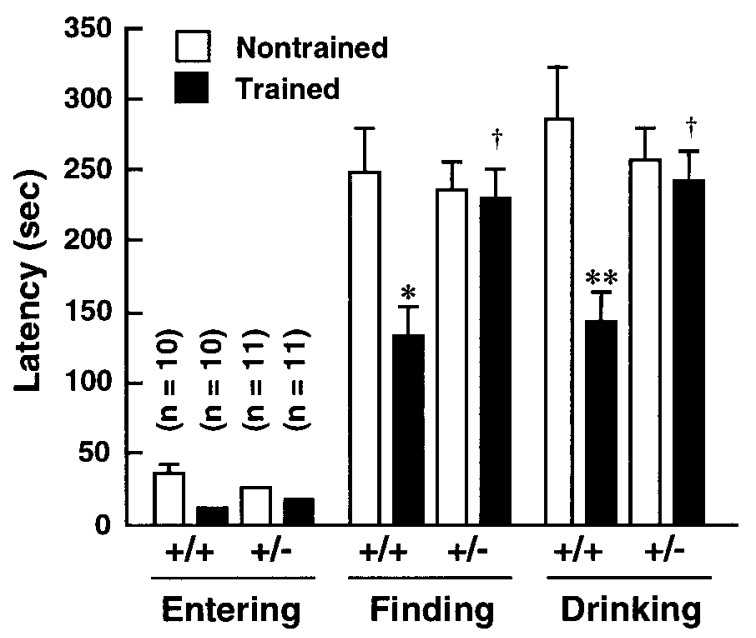

B

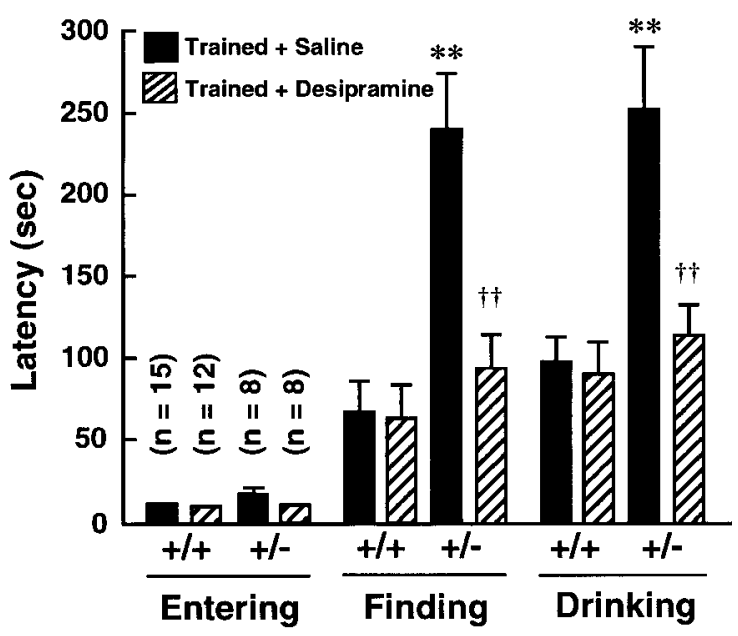

Figure 3. Latent learning in the water-finding test. Entering, finding, and drinking latencies are shown. Values represent mean \pm SEM of data. $A$, Impaired learning performance in the heterozygous mutant. The wildtype and heterozygous mutant mice were explored to the water-finding test. Two-way ANOVA showed a significant interaction between genotype and training for finding latency $\left(F_{(1,38)}=4.662, p<0.05\right)$ and for drinking latency $\left(F_{(1,38)}=5.827, p<0.05\right) .{ }^{*} p<0.05$ versus nontrained wild-type mice; ${ }^{* *} p<0.01$ versus nontrained wild-type mice; and $\dagger p<$ 0.05 versus trained wild-type, significant differences according to Newman-Keuls test. $B$, Recovery from the learning defects by desipramine treatment. Mice were treated with saline or desipramine $(7.5 \mathrm{mg} / \mathrm{kg}$, i.p.) 45 min before training and were tested for the same task. ANOVA indicated a significant interaction between genotype and treatment for finding latency $\left(F_{(1,39)}=12.045, p<0.005\right)$ and for drinking latency $\left(F_{(1,39)}=10.397, p<0.005\right) .{ }^{* *} p<0.01$ versus saline-treated wild-type mice; $\dagger \dagger p<0.01$ versus saline-treated heterozygotes, significant differences according to Newman-Keuls test.

cue-dependent avoidance from an electric foot shock was scored. The sensitivity to pain was measured by the tail-flick test. The flick latency was indistinguishable between the wild-type $(6.2 \pm$ $0.3 \mathrm{sec}, n=4)$ and heterozygous mutant $(6.6 \pm 0.2 \mathrm{sec}, n=4)$, indicating that the mutant could respond normally to the foot shock. When the mice were subjected to the active avoidance task (Fig. $4 A$ ), the wild type showed a normal acquisition of the avoidance responses, which reached the plateau on the fifth trial day with $92 \%$ success of avoidance. In contrast, the heterozygous
A

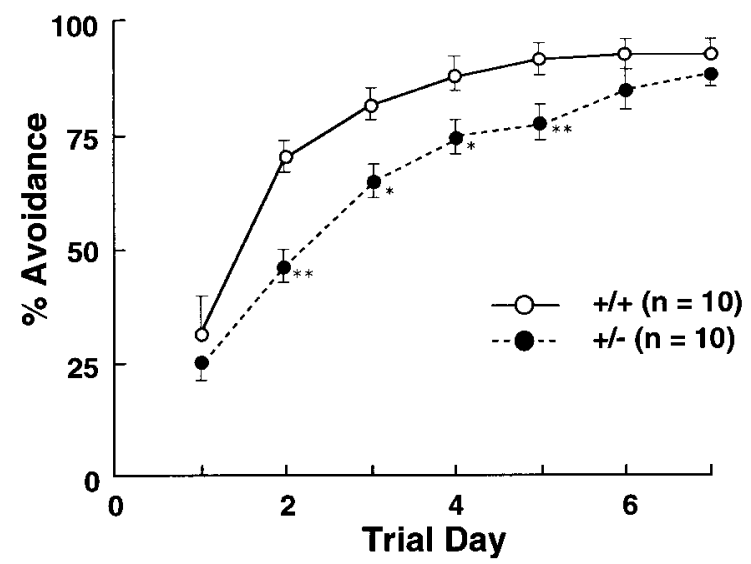

B

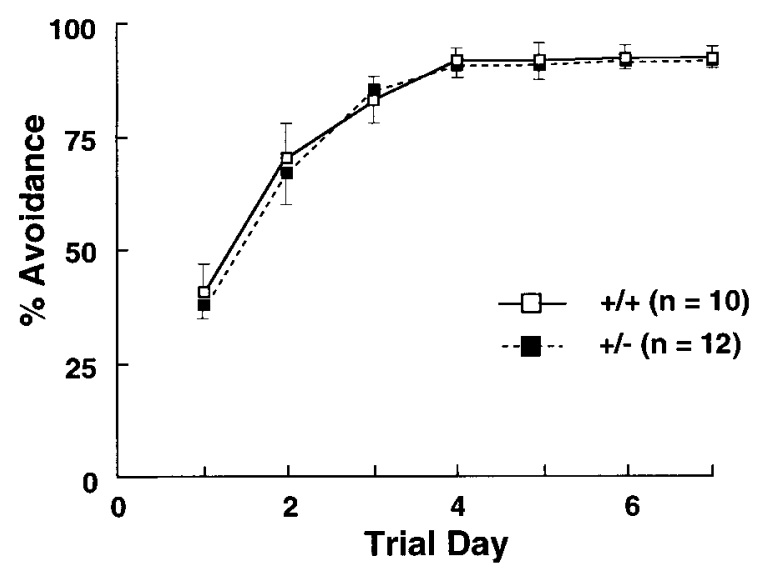

Figure 4. Active avoidance task. The wild-type and heterozygous mutant mice were tested with the shuttle box paradigm. Mice were treated intraperitoneally with saline or desipramine $(7.5 \mathrm{mg} / \mathrm{kg})$ every day $45 \mathrm{~min}$ before the trial. Percentage of successful avoidances in 10 trials/d is plotted. Values indicate mean \pm SEM of data. In the saline-injected animals $(A)$, according to two-way ANOVA there were significant main effects between genotypes $\left(F_{(1,22)}=18.513, p<0.001\right)$ and among trial days $\left(F_{(6,132)}=83.730, p<0.001\right)$. The interaction between the two factors was significant $\left(F_{(6,132)}=2.531, p<0.05\right)$. * $p<0.05 ; * * p<0.01$, significant differences from the wild-type mice according to the NewmanKeuls test. In the desipramine-treated animals $(B)$, the main effect among trial days was significant (ANOVA, $F_{(6,120)}=63.776, p<0.001$ ), the main effect between genotypes was not significant, and there was no interaction between genotype and trial day.

mutant learned more slowly, and the rate of the successful response was significantly lower than that of the wild-type mice up to the fifth trial day (Fig. $4 A$ ). The success of avoidance in the fifth trial was $75 \%$. There was a significant interaction between the genotypes and trial numbers $\left(F_{(6,132)}=2.531, p<0.05\right)$. The impairment of active avoidance in the heterozygous mutant was restored by desipramine treatment ( $7.5 \mathrm{mg} / \mathrm{kg}$, i.p.) (Fig. 4B). These results suggest that the impaired active avoidance in the mutant is attributed to the reduced noradrenaline level in the brain.

To evaluate the performance of associative learning in the $\mathrm{TH}^{+/-}$heterozygous mutant by a different learning paradigm, we conducted the tone-cued fear conditioning (Davis et al., 1994; LeDoux, 1995). In this paradigm, a foot shock US was associated with a tone CS during the training session, and probability of the 
A

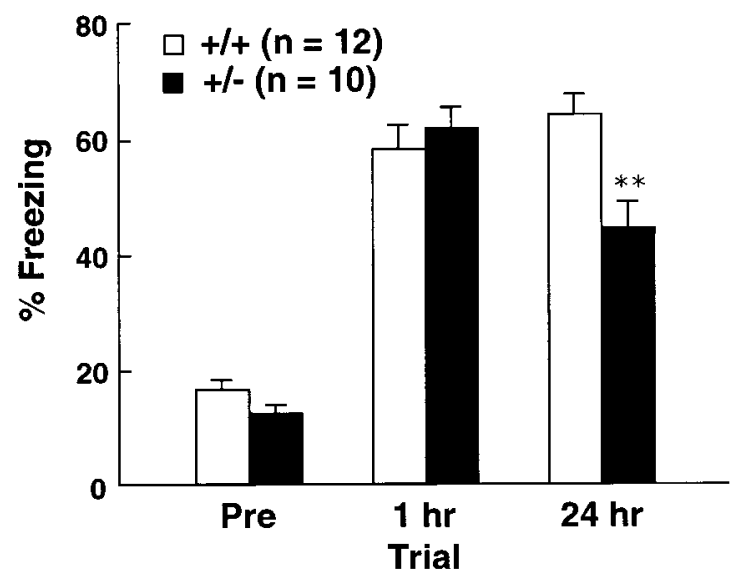

B

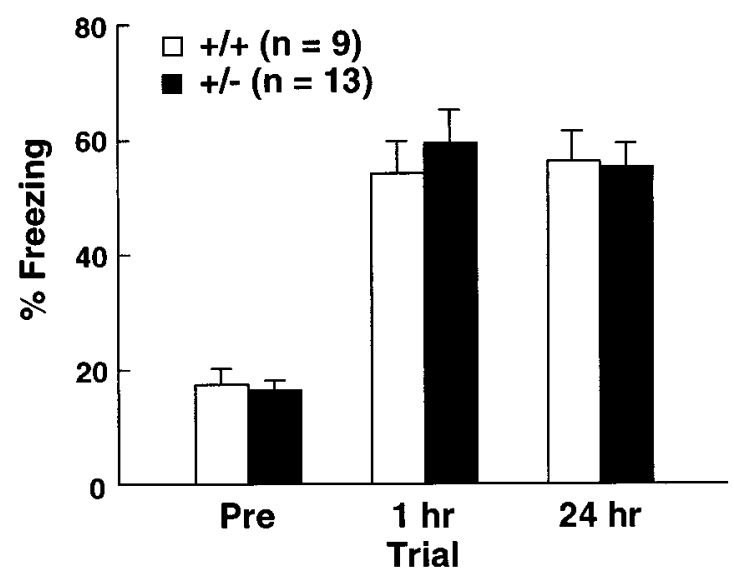

Figure 5. Cued fear conditioning. The wild-type and heterozygous mutant mice were tested 1 and $24 \mathrm{hr}$ after conditioning for freezing in the presence of a continuous sound for $1 \mathrm{~min}$. Freezing response was tested in advance in the preconditioning period of $1 \mathrm{~min}$ (Pre). Mice were treated intraperitoneally with saline or desipramine $(15 \mathrm{mg} / \mathrm{kg})$ after the conditioning phase. Values indicate mean \pm SEM of data. In the salineinjected animals $(A)$, there was a significant interaction between genotype and trial time (ANOVA, $\left.F_{(2,40)}=4.94, p<0.05\right)$. $* * p<0.01$, significant difference from the wild-type mice according to the Newman-Keuls test. In the desipramine-injected animals $(B)$, there was no interaction between the two factors.

freezing behavior to the subsequent tone CS was measured (Fig. $5 A$ ). At $1 \mathrm{hr}$ after the conditioning, both wild-type and heterozygous mutant mice exhibited similar probability of freezing response with no significant difference. The probability was by approximately three times higher than that measured in the preconditioning period, indicating that the two genotypes learned association of the tone CS and the foot shock US. In contrast, at $24 \mathrm{hr}$ after the conditioning, the wild type sustained the performance, whereas the freezing probability in the mutant was moderately but significantly reduced from the value at $1 \mathrm{hr}$ after the conditioning. These results suggest that memory storage or retrieval was mildly impaired in the heterozygous mutants, although they exhibited normal learning acquisition. Again, the learning deficit in the heterozygous mutant was restored by desipramine treatment (15 mg/kg, i.p.) after the conditioning (Fig. 5B), sug-
A
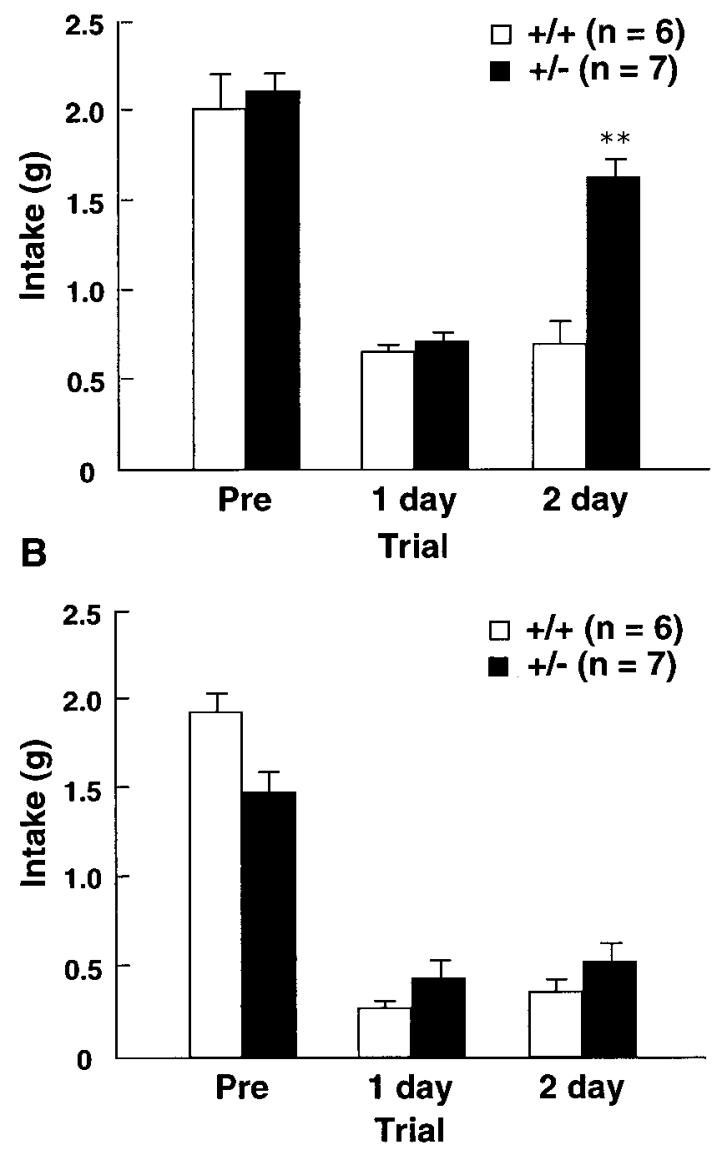

Figure 6. Conditioned taste aversion. Mice were tested 1 and $2 \mathrm{~d}$ after conditioning by measuring sucrose intake for $10 \mathrm{~min}$ from one drinking bottle. Sucrose intake in the preconditioning period (Pre) is shown. Mice were treated intraperitoneally with saline or desipramine $(15 \mathrm{mg} / \mathrm{kg})$ after the conditioning phase. Values indicate mean \pm SEM of data. In the saline-injected animals $(A)$, there was a significant interaction between genotype and trial day (ANOVA, $F_{(2,22)}=4.15, p<0.05$ ). ${ }^{* *} p<0.01$, significant difference from the wild-type mice according to the NewmanKeuls test. In the desipramine-treated animals $(B)$, there was no interaction between the two factors.

gesting that normal noradrenergic activity is required for longterm memory of the conditioned fear.

To further evaluate the performance of associative learning, we examined the conditioned taste aversion that requires an association between a taste CS and visceral malaise-inducing US (Yamamoto et al., 1994, 1995). In the training session, the animals receive a novel taste $(0.5 \mathrm{~m}$ sucrose $)$ from a drinking bottle as a $\mathrm{CS}$, followed by an intraperitoneal injection of lithium chloride as a US. The US induces a sickness soon after the injection, and thus conditioned animals show aversive behavior to the taste CS. Acquisition and retention of aversive responses were tested after the conditioning to $0.5 \mathrm{M}$ sucrose as the taste CS (Fig. $6 \mathrm{~A}$ ). On day 1 after the conditioning, both wild-type and heterozygous mutant mice exhibited the taste aversion to a similar extent. The sucrose intake was significantly lower than that in the preconditioning control period. On day 2, the wild type continued to exhibit aversive responses, whereas the heterozygous mutant took sucrose to almost the same extent as during the preconditioning period. Post-training desipramine treatment ( $15 \mathrm{mg} / \mathrm{kg}$, i.p.) also 
A
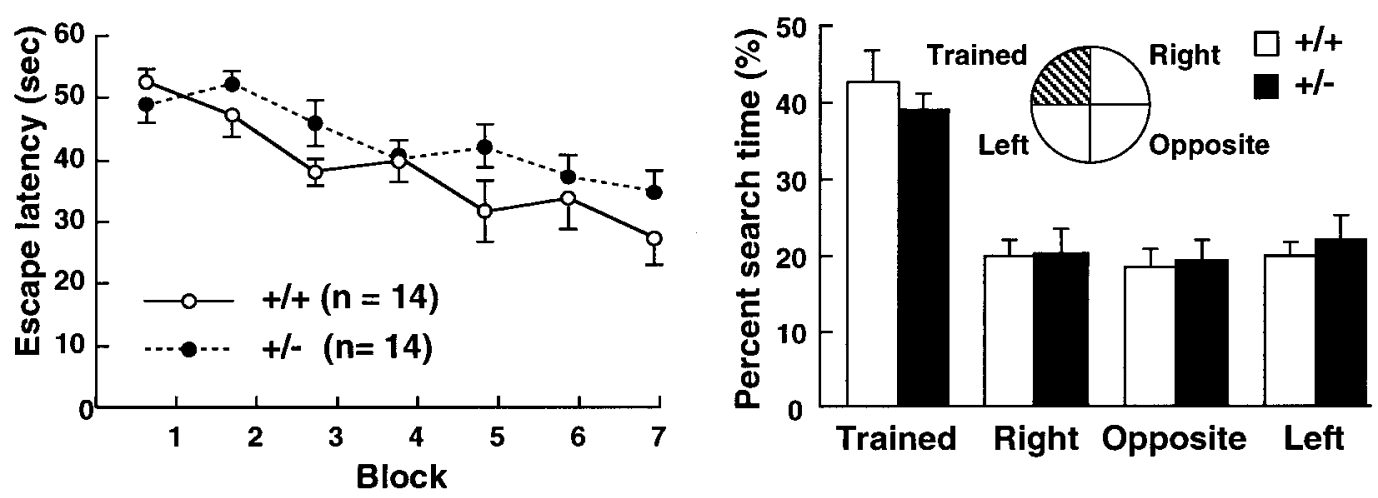

B

Schaffer collateral-CA1
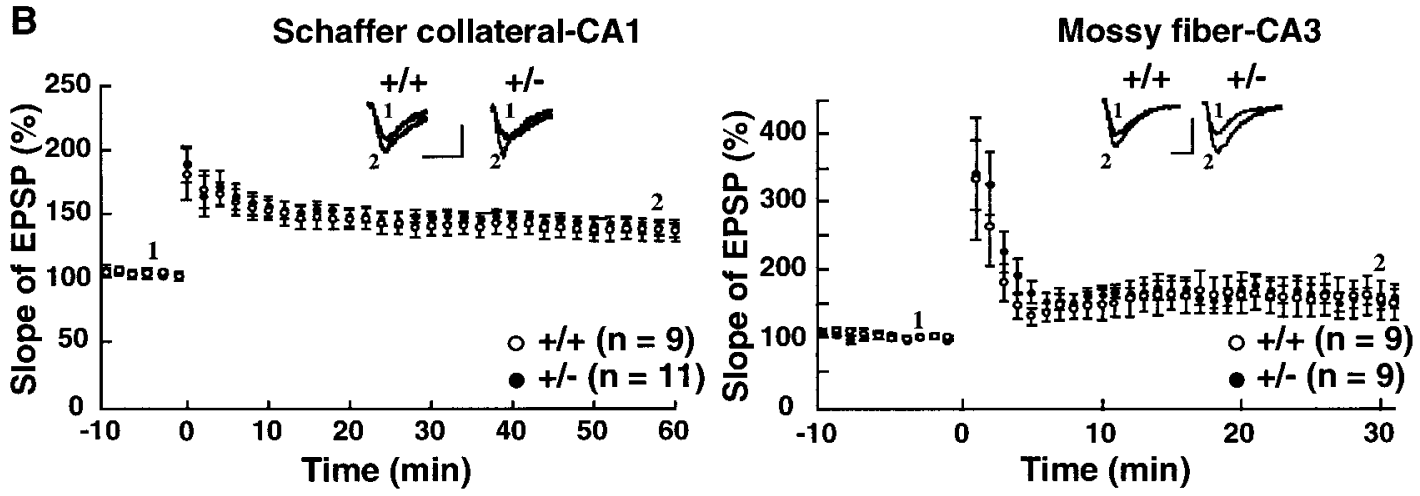

Figure 7. Spatial learning and hippocampal LTP. A, Morris water maze task. Left panel indicates escape latency in each block of the hidden platform water maze test. Values indicate mean \pm SEM of data. Two-way ANOVA showed a significant main effect among trial blocks $\left(F_{(6,144)}=9.712, p<0.001\right)$, but the main effect between genotypes was not significant. Right panel indicates the quadrant search time in the probe test. ANOVA showed a significant main effect among quadrants $\left(F_{(3,96)}=23.221, p<0.001\right)$ but not between genotypes. Both wild-type and heterozygous mice spent more time in the trained quadrant than in the others (trained quadrant $>$ other quadrants, $p<0.01$, Newman-Keuls test). $B$, Hippocampal LTP. The field EPSP slopes in the CA1 (left panel) or CA3 (right panel) region are expressed as a percentage of the baseline taken before tetanic stimulation. Values indicate mean \pm SEM of data. Inset traces are typical field EPSPs obtained from wild-type and heterozygous mutant slices at the time points indicated in each graph. The values of EPSP slopes exhibited no significant difference between the two genotypes (ANOVA). Calibration: left panel, $20 \mathrm{msec}, 1 \mathrm{mV}$ for the CA1 traces; right panel, $20 \mathrm{msec}, 0.5 \mathrm{mV}$ for the CA3 traces.

restored the learning performance in the heterozygote (Fig. $6 B$ ). These findings are consistent with the results obtained from the cued fear conditioning and suggest that the noradrenaline system plays an important role in the formation of the associative longterm memory.

\section{Normal spatial learning and hippocampal LTP in the mutant}

Noradrenaline has various electrophysiological actions on the hippocampal neurons, including an enhancement of LTP (Huang and Kandel, 1996; Raman et al., 1996; Thomas et al., 1996). These data suggest a possible modulatory role of noradrenaline in the hippocampus-dependent behaviors. We thus conducted the hidden platform water maze task to evaluate the performance of the hippocampus-dependent spatial learning. Both wild-type and heterozygous mutant mice learned the task and displayed no difference in escape latency between the two genotypes (Fig. 7A). After the mice learned the quadrant in which the hidden platform was present, the platform was removed and the mice were subjected to the probe test. Both wild-type and heterozygous mutant tended to search in the correct quadrant and spent more time there than in the other three quadrants $(p<0.01)$ (Fig. 7A). Consistent with these behavioral results, we found that LTP was normal in the heterozygous mutant mice (Fig. $7 B$ ). When measured at $60 \mathrm{~min}$ after the tetanus, the slope of the field EPSP in the CA1 region potentiated to $136 \pm 5$ and $136 \pm 9 \%$ of the baseline value for the wild-type and heterozygous mutants, respectively. The field EPSP slope in the CA3 region was $156 \pm 28$ and $155 \pm 13 \%$ of baseline for the wild-type and heterozygous mutant, respectively. These behavioral and electrophysiological data indicate that the decrease in noradrenaline level in the heterozygote does not cause significant impairment of hippocampal functions, suggesting that the hippocampus-dependent learning is resistant to the reduction in the noradrenergic activity.

\section{DISCUSSION}

The present study demonstrates that the noradrenaline system plays an important role in memory formation in certain learning paradigms. The diminished $\mathrm{TH}$ activity in mice carrying a single mutated allele of the $\mathrm{TH}$ gene resulted in a moderate reduction in noradrenaline synthesis and secretion in the brain. The mutant mice exhibited impairment in the latent learning and in three distinct forms of associative learning, whereas the spatial learning and hippocampal LTP remained intact in the mutant. The impaired performance in the latent and associative learning para- 
digms was restored by the drug-induced stimulation of noradrenergic neuronal activity, suggesting that the learning deficits in the mutant are attributable to the reduced noradrenaline level because of the low TH activity.

Our preliminary histological analysis with cresyl violet staining indicated normal morphology of the brain in $\mathrm{TH}$ heterozygous mutant at adulthood (data not shown). We did not find any structural abnormalities in various brain regions of the mutant, including the olfactory bulb, cerebral cortex, hippocampus, amygdala, thalamus, hypothalamus, midbrain, and pons medulla. These results suggest that a mild reduction in noradrenaline level does not cause significant developmental abnormalities of the brain, at least at the light microscopic level we have examined so far. Therefore, the behavioral deficits observed in the mutant might well be associated with the functional disturbance in the noradrenaline system.

Latent learning is considered to depend on attention and arousal (Mackintosh, 1975; Ettenberg et al., 1983). The waterfinding test adopted in this study has been used to assess changes in neuropsychological functions caused by drugs that enhance or repress catecholaminergic activity (Ichihara et al., 1989, 1993a,b). Previous behavioral studies suggest that the noradrenaline system can be implicated in attention and arousal in both rodents and primates (Sara and Devauges, 1989; Devauges and Sara, 1990; Cole and Robbins, 1992; Aston-Jones et al., 1994). At the cellular level, noradrenaline is known to enhance neuronal responsiveness to sensory input by inhibiting the background activity of the target neurons and to increase the selectivity of the responses to relevant stimuli (Foote et al., 1983; Robbins and Everitt, 1995). The enhancement of the signal-to-noise ratio in the sensory responses appears to be the cellular basis by which the noradrenaline system controls attention and arousal states. These results suggest that the impaired latent learning in the $\mathrm{TH}^{+/-}$heterozygous mutant may be attributed to the altered state in attention and arousal because of the reduced noradrenaline level.

The $\mathrm{TH}^{+/-}$heterozygous mutant displayed modest deficits in three kinds of associative learning paradigms, including active avoidance, cued fear conditioning, and conditioned taste aversion. In the cued fear conditioning and conditioned taste aversion, the heterozygous mutant mice, when tested shortly after the training, exhibited learning performance to almost the same extent as the wild-type mice. However, when tested again after a certain time interval, the mutant mice displayed poor performance as though they had forgotten the task. These results suggest that, in the heterozygous mutants, the short-term memory formation is normal but the consolidation process for the long-term memory is impaired. In the active avoidance, the heterozygous mice learned the performance more slowly than the wild-type animals during the successive training. In this paradigm, the performance was examined daily at $24 \mathrm{hr}$ intervals. Considering the results obtained from the other two associative learning paradigms, the impairment in the active avoidance can be explained by the defect in the consolidation process of the memory. The defect in memory consolidation after daily training may lead to the slow acquisition rate of learning performance in the mutant. Together, the data indicate that the central noradrenaline system plays a key role in long-term memory formation of conditioned learning. This process is highly susceptible to a reduction in the noradrenergic activity.

Several behavioral studies have indicated that the three forms of associative learning we conducted here require the amygdala and its linking pathways. In the tone-dependent associative learn- ing, the lateral nucleus of the amygdala is reported to link the acoustic CS via the thalamo-amygdala or thalamo-corticoamygdala pathway with the fear response (LeDoux et al., 1990; Romanski and LeDoux, 1992). In the active avoidance task, one of the output projections from the amygdala to the nucleus accumbens provides an important route by which the associative processes in the amygdala access to the emotional response (Everitt et al., 1991). In the conditioned taste aversion task, the gustatory CS is thought to be integrated with the visceral aversive stimulus in the lateral nucleus group of the amygdala (Yamamoto et al., 1994, 1995). Previous pharmacological studies have suggested that the noradrenaline system in the amygdala is implicated in memory formation. The infusion of noradrenaline into the amygdala enhances memory consolidation in the passive avoidance task via $\beta$-adrenergic receptors (Gallagher et al., 1977; McGaugh et al., 1996; Quirarte et al., 1997). Also, the neurotoxic depletion of the noradrenaline system in the amygdala attenuates memory formation of conditioned taste aversion (Borsini and Rolls, 1984). These results suggest that impairment of associative learning in the heterozygous mutant may be attributed in part to dysfunction of the amygdala.

We need to consider the role of the cerebral cortex in long-term memory formation to explain the impaired associative learning in the TH mutant. The perirhinal cortex is considered to be required for conditioned learning dependent on auditory or visual stimuli, particularly during the post-training phase (Campeau and Davis, 1995; Corodimas and LeDoux, 1995). Lesion of the insular cortex, which contains the gustatory cortex, disrupts the retention of the taste aversion (Yamamoto et al., 1980; Gallo et al., 1992). Also, activation of some protein kinases in the insular cortex is involved in consolidation of long-term taste memory (Berman et al., 1998). Anatomically, noradrenergic fibers project to the entire cerebral cortex (Moore and Card, 1984). They modulate the excitability of pyramidal neurons in various areas of the cerebral cortex (Foote et al., 1983; Robbins and Everitt, 1995). Therefore, dysfunction in the cerebral cortex attributable to the reduced noradrenergic activity in the mutant may lead to the impairment in long-term memory formation.

In this study, we used desipramine to restore the behavioral deficits in the TH mutant mice. Desipramine inhibits the reuptake of noradrenaline into presynaptic terminals. The resulting elevation of extracellular noradrenaline level acutely stimulates adrenergic receptors. Chronic exposure of desipramine is known to cause downregulation or desensitization of the receptors. According to a previous study (Seo et al., 1999), chronic treatment of desipramine $(10 \mathrm{mg} / \mathrm{kg}$, once daily for $10 \mathrm{~d}$ ) produces downregulation of $\beta$-adrenergic receptors in the brain. In our study, we treated the animals with a single injection of desipramine $(7.5$ or $15 \mathrm{mg} / \mathrm{kg}$ ) for the water-finding, fear conditioning, and taste aversion tests, or with a daily injection for $7 \mathrm{~d}$ of desipramine $(7.5$ $\mathrm{mg} / \mathrm{kg}$ ) for the active avoidance test. These treatment conditions do not seem to induce downregulation of adrenergic receptors. The pharmacological restoration of the behavioral deficits is mainly attributed to the stimulatory effects on the receptors of desipramine, and the restoration may not be associated with downregulation of the receptors.

Anti-depressants are generally known to take several days to develop the efficacy in humans. In contrast, desipramine treatment efficiently improved the behavioral deficits in the mutant mice. In our study, the primary cause of the behavioral deficits was a reduction in noradrenaline metabolism attributable to the heterozygous mutation in the $\mathrm{TH}$ gene. Therefore, the deficits 
were clearly restored by the desipramine-induced stimulation of noradrenaline system. Alterations in the central noradrenaline system also seem to be implicated in the pathological states of several neuropsychiatric disorders, but they may not simply result from the reduced noradrenaline metabolism. Changes in other neurotransmitter systems may be also involved in the disorders. Anti-depressants may improve the pathological states gradually through complex mechanisms.

For a clearer understanding of the behavioral abnormalities in the TH mutant, it is of importance to determine alterations in noradrenaline metabolism and neuronal activity correlated with the behavior in specific brain regions, such as amygdala and some cortical regions. Our mutant mice should provide a genetic model for studying the mechanism by which the noradrenaline system controls memory formation. There is a possibility that the reduced noradrenaline metabolism during development may cause modulations in a variety of physiological properties, such as the binding density of adrenergic receptors, their intracellular signal transduction, and interaction with other neurotransmitters. We cannot rule out these pleiotropic effects of developmental reduction of noradrenaline. However, our mutant mice are useful to elucidate possible alterations in physiological states resulting from the alleviation of the central noradrenaline system in the future.

\section{REFERENCES}

Archer T, Ögren SO, Johansson G, Ross SB (1982) DSP4-induced two way active avoidance impairment in rats: involvement of central and not peripheral noradrenaline depletion. Psychopharmacology 76:303-309.

Aston-Jones G, Rajkowski J, Kubiak P, Alexinsky T (1994) Locus coeruleus neurons in monkey are selectively activated by attended cues in a vigilance task. J Neurosci 14:4467-4480.

Berman DE, Hazvi S, Rosenblum K, Seger R, Dudai Y (1998) Specific and differential activation of mitogen-activated protein kinase cascades by unfamiliar taste in the insular cortex of the behaving rat. J Neurosci 18:10037-10044.

Borsini F, Rolls ET (1984) Role of noradrenaline and serotonin in the basolateral region of the amygdala in food preferences and learned taste aversion in the rat. Physiol Behav 33:37-43.

Campeau S, Davis M (1995) Involvement of subcortical and cortical afferents to the lateral nucleus of the amygdala in fear conditioning measured with fear-potentiated startle in rats trained concurrently with auditory and visual conditioned stimuli. J Neurosci 15:2312-2327.

Charney DS, Woods SW, Goodman WK, Heninger GR (1987) Neurobiological mechanisms of panic anxiety: biochemical and behavioral correlates of yohimbine-induced panic attacks. Am J Psychiatry 144:1030-1036.

Charney DS, Woods SW, Heninger GR (1992) Noradrenergic neuronal dysregulation in panic disorder: the effects of intravenous yohimbine and clonidine in panic disorder patients. Acta Psychiatr Scand 86:273-282.

Cole BJ, Robbins TW (1992) Forebrain norepinephrine: role in controlled information processing in the rat. Neuropsychopharmacology 7:129-142.

Corodimas KP, LeDoux JE (1995) Disruptive effects of posttraining perirhinal cortex lesions on conditioned fear: contributions of contextual cues. Behav Neurosci 109:613-619.

Davis M, Rainnie D, Cassell M (1994) Neurotransmission in the rat amygdala related to fear and anxiety. Trends Neurosci 17:208-214.

Devauges V, Sara SJ (1990) Activation of the noradrenergic system facilitates an attentional shift in the rat. Behav Brain Res 39:19-28.

Dohlman HG, Thorner J, Caron MG, Lefkowitz RJ (1991) Model systems for the study of seven-transmembrane-segment receptors. Annu Rev Biochem 60:653-688.

Ettenberg A, Le Moal M, Koob GF, Bloom FE (1983) Vasopressin potentiation in the performance of a learned appetitive task: reversal by a pressor antagonist analog of vasopressin. Pharmacol Biochem Behav 18:645-647.

Everitt BJ, Morris K, O'Brien A, Robbins TW (1991) The basolateral amygdala-central striatal system and conditioned place preference: further evidence of limbic-striatal interactions underlying rewardrelated processes. Neuroscience 42:1-18.

Foote SL, Bloom FE, Aston-Jones G (1983) Nucleus locus ceruleus: new evidence of anatomical and physiological specificity. Physiol Rev 63:844-914.

Franklin KBJ, Paxinos G (1997) The mouse brain in stereotaxic coordinates. San Diego: Academic.

Gallagher M, Kapp BS, Musty RE, Driscoll PA (1977) Memory formation: evidence for a specific neurochemical system in the amygdala. Science 198:423-425.

Gallo M, Rodan G, Bures J (1992) Differential involvement of gustatory insular cortex and amygdala in the acquisition and retrieval of conditioned taste aversion in rats. Behav Brain Res 52:91-97.

Grant SG, O’Dell TJ, Karl KA, Stein PL, Soriano P, Kandel ER (1992) Impaired long-term potentiation, spatial learning, and hippocampal development in fyn mutant mice. Science 258:1903-1910.

Huang Y-Y, Kandel ER (1996) Modulation of both the early and the late phase of mossy fiber LTP by the activation of $\beta$-adrenergic receptors. Neuron 16:611-617.

Ichihara K, Nabeshima T, Kameyama T (1989) Differential effects of pimozide and SCH23390 on acquisition of learning in mice. Eur J Pharmacol 164:189-195.

Ichihara K, Nabeshima T, Kameyama T (1993a) Dopaminergic agonists impair latent learning in mice: possible modulation by noradrenergic function. J Pharmacol Exp Ther 264:122-128.

Ichihara K, Nabeshima T, Kameyama T (1993b) Mediation of dopamine D1 and D2 receptors in the effects of GBR 12909 on latent learning and locomotor activity in mice. Eur J Pharmacol 234:155-163.

Kobayashi K, Morita S, Mizuguchi T, Sawada H, Yamada K, Nagatsu I, Fujita K, Nagatsu T (1994) Functional and high level expression of human dopamine $\beta$-hydroxylase in transgenic mice. J Biol Chem 269:29725-29731.

Kobayashi K, Morita S, Sawada H, Mizuguchi T, Yamada K, Nagatsu I, Hata T, Watanabe Y, Fujita K, Nagatsu T (1995) Targeted disruption of the tyrosine hydroxylase locus results in severe catecholamine depletion and perinatal lethality in mice. J Biol Chem 270:27235-27243.

LeDoux JE (1995) Emotion: clues from the brain. Annu Rev Psychol 46:209-235.

LeDoux JE, Cicchetti P, Xagoraris A, Romanski LM (1990) The lateral amygdaloid nucleus: sensory interface of the amygdala in fear conditioning. J Neurosci 10:1062-1069.

Mackintosh NJ (1975) A theory of attention: variations in the associability of stimuli with reinforcement. Psychol Rev 82:276-298.

Manabe T, Noda Y, Mamiya T, Katagiri H, Houtani T, Nishi M, Noda T, Takahashi T, Sugimoto T, Nabeshima T, Takeshima H (1998) Facilitation of long-term potentiation and memory in mice lacking nociception receptors. Nature 394:577-581.

McGaugh JL, Cahill L, Roozendaal B (1996) Involvement of the amygdala in memory storage: interaction with other brain systems. Proc Natl Acad Sci USA 93:13508-13514.

Moore RY, Card JP (1984) Noradrenaline-containing neuron systems. In: Handbook of chemical neuroanatomy, Vol 2 (Björklund A, Hökfelt T, eds), pp 123-156. Amsterdam: Elsevier.

Nagatsu T, Levitt M, Udenfriend S (1964) Tyrosine hydroxylase: the initial step in norepinephrine biosynthesis. J Biol Chem 239:2910-2917.

Nakahara D, Ozaki N, Nagatsu T (1993) In vivo microdialysis of neurotransmitters and their metabolites. In: Methods in neurotransmitter and neuropeptide research (Parvez SH, Naoi M, Nagatsu T, eds), pp 219248. Amsterdam: Elsevier.

Nicoll RA, Malenka RC, Kauer JA (1990) Functional comparison of neurotransmitter receptor subtypes in mammalian central nervous system. Physiol Rev 70:513-565.

Nishii K, Matsushita N, Sawada H, Sano H, Noda Y, Mamiya T, Nabeshima T, Nagatsu I, Hata T, Kiuchi K, Yoshizato H, Nakashima K, Nagatsu T, Kobayashi K (1998) Motor and learning dysfunction during postnatal development in mice defective in dopamine neuronal transmission. J Neurosci Res 54:450-464.

Oades RD (1987) Attention deficit disorder with hyperactivity (ADHD): the contribution of catecholaminergic activity. Prog Neurobiol 29:365-391.

Oike Y, Hata A, Mamiya T, Kaname T, Noda Y, Suzuki M, Yasue H, Nabeshima T, Araki K, Yamamura K (1999) Truncated CBP protein leads to classical Rubinstein-Taybi syndrome phenotype in mice: implications for a dominant-negative mechanism. Hum Mol Genet 8:387-396. 
Quirarte GL, Roozendaal B, McGaugh JL (1997) Glucocorticoid enhancement of memory storage involves noradrenergic activation in the basolateral amygdala. Proc Natl Acad Sci USA 94:14048-14053.

Raman IM, Tong G, Jahr CE (1996) $\beta$-Adrenergic regulation of synaptic NMDA receptors by cAMP-dependent protein kinase. Neuron 16:415-421.

Rios M, Habecker B, Sasaoka T, Eisenhofer G, Tian H, Landis S, Chikaraishi D, Roffler-Tarlov S (1999) Catecholamine synthesis is mediated by tyrosinase in the absence of tyrosine hydroxylase. J Neurosci 19:3519-3526.

Robbins TW, Everitt BJ (1995) Central norepinephrine neurons and behavior. In: Psychopharmacology: the fourth generation of progress (Bloom FE, Kupfer DJ, eds), pp 363-372. New York: Raven.

Romanski LM, LeDoux JE (1992) Equipotentiality of thalamoamygdala and thalamo-cortico-amygdala circuits in auditory fear conditioning. J Neurosci 12:4501-4509.

Rubin AL, Price LH, Charney DS, Heninger GR (1985) Noradrenergic function and the cortisol response to dexamethasone in depression. Psychiatry Res 15:5-15.

Sara SJ, Devauges V (1989) Idazoxan, an $\alpha$-2 antagonist, facilitates memory retrieval in the rat. Behav Neural Biol 51:401-411.

Schatzberg AF, Samson JA, Bloomingdale KL, Orsulak PJ, Gerson B, Kizuka PP, Cole JO, Schildkraut JJ (1989) Toward a biochemical classification of depressive disorders. X. Urinary catecholamines, their metabolites, and D-type scores in subgroups of depressive disorders. Arch Gen Psychiatry 46:260-268.

Seo DO, Shin CY, Lee CJ, Dailey JW, Reith ME, Jobe PC, Ko KH (1999) Effect of alterations in extracellular norepinephrine on adrenoceptors: a microdialysis study in freely moving rats. Eur J Pharmacol 365:39-46.

Thomas MJ, Moody TD, Makhinson M, O’Dell TJ (1996) Activitydependent $\beta$-adrenergic modulation of low frequency stimulation induced LTP in the hippocampal CA1 region. Neuron 17:475-482.

Yamamoto T, Matsuo R, Kawamura Y (1980) Localization of the cortical gustatory area in rats and its role in taste discrimination. J Neurophysiol 44:440-455.

Yamamoto T, Shimura T, Sato N, Yasoshima Y, Sakai N (1994) Neural substrates for conditioned taste aversion in the rat. Behav Brain Res 65:123-137.

Yamamoto T, Fujimoto Y, Shimura T, Sakai N (1995) Conditioned taste aversion in rats with excitotoxic brain lesions. Neurosci Res 22:31-49.

Zhou Q-Y, Quaife CJ, Palmiter RD (1995) Targeted disruption of the tyrosine hydroxylase gene reveals that catecholamines are required for mouse fetal development. Nature 374:640-643.

Zigmond RE, Schwarzschild MA, Rittenhouse AR (1989) Acute regulation of tyrosine hydroxylase by nerve activity and by neurotransmitters via phosphorylation. Annu Rev Neurosci 12:415-461. 